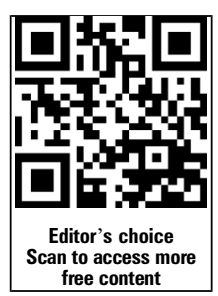

${ }^{1}$ Painted Dog Research, Perth, Western Australia, Australia ${ }^{2}$ Curtin University, Perth, Western Australia, Australia ${ }^{3}$ Cancer Council WA, Perth, Western Australia, Australia

\section{Correspondence to}

Cassandra Clayforth, Cancer Council Western Australia,

15 Bedbrook Place, Shenton Park, WA 6008, Australia;

cclayforth@cancerwa.asn.au

Received 8 May 2014 Accepted 13 January 2015 Published Online First 9 February 2015

\section{SLinked}

- http://dx.doi.org/10.1136/ tobaccocontrol-2015-052233

\section{CrossMark}

To cite: Amonini $C$, Pettigrew S, Clayforth C. Tob Control 2015;24:436-441.

\title{
The potential of shame as a message appeal in antismoking television advertisements
}

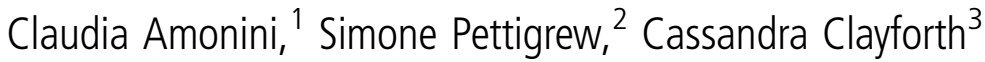

\begin{abstract}
Background As smoking is increasingly de-normalised, different messages may become more appropriate for use in tobacco control advertisements to reflect the changing social environment. To date, more commonly used messages have included fear appeals relating to physical health and guilt appeals focusing on the effects of smoking on loved ones.
\end{abstract}

Objective This study investigated the relative effectiveness of varying advertising appeals to promote smoking cessation. The study was conducted in Australia, where only $12 \%$ of the population smokes and legislation restricts smoking in many public places. The aim was to provide insight into ways to motivate the small segment of existing smokers to consider quitting.

Methods Across a qualitative phase and an ad testing phase, shame was found to be highly salient to current smokers and those who had quit recently. On the basis of these results, a television advertisement featuring a shame appeal was developed and broadcast. The ad featured various scenarios of individuals hiding their smoking from others. The campaign was evaluated using the measures of awareness, believability, perceived relevance and smoking behaviours.

Results The shame appeal television advertisement was found to resonate with smokers and encourage quitting/reducing behaviours. Around 4 in 5 (78\%) smokers surveyed recalled seeing the ad, almost all of whom could nominate at least one correct take-out message (94\%). Around three-quarters (72\%) found the ad to be personally relevant and half (53\%) reported that they had successfully quit, attempted to quit or cut down the number of cigarettes they smoked since the start of the campaign.

Conclusions The use of shame appeals may be an effective method of motivating smokers to quit in an environment where they are members of a small minority and supportive legislation exists to discourage smoking in public places.

\section{INTRODUCTION}

Tobacco control efforts to date have relied heavily on mass media to educate the public about the harms of smoking and persuade smokers to quit. ${ }^{1}$ Comprehensive tobacco control programmes that include mass media advertising campaigns have been recognised as contributing to significant reductions in smoking rates. ${ }^{1}{ }^{2}$ For example, smoking rates in Australia have halved in recent decades, decreasing from $24 \%$ in 1991 to $12 \%$ in 2013. ${ }^{3}$ This compares favourably to other countries such as the UK and the US where rates are $20 \%$ and $18 \%$ respectively. ${ }^{45}$

The substantial reduction in smoking in Australia has been attributed to the implementation of a broad range of tobacco control measures that have included hefty taxation on tobacco products, packaging restrictions, bans on tobacco advertising, strong public health advocacy, and a continual effort by key health organisations to educate the general population. ${ }^{6} 7$ The sustained public education programme has included numerous television advertisements, which have typically focused on the physical harms from smoking and the loss experienced by loved ones due to the smoker's premature death. ${ }^{8} \quad 9$ These advertisements have achieved high levels of awareness and successfully complemented other tobacco control interventions. ${ }^{6}$ However, there are groups of smokers who have remained immune to past campaigns and hence may require alternative approaches to encourage them to quit. ${ }^{9}$ Such approaches are likely to include advertising appeals that have not been used widely to date, but that resonate with those individuals who continue to smoke despite ongoing exposure to messages using health and guilt themes.

The selection of appropriate alternative advertising approaches is hindered by a lack of theoretical understanding of the types of message appeals that are most effective under particular circumstances and the mechanisms via which effects occur. ${ }^{10}{ }^{11}$ In addition, there is debate about the ethicality of approaches that rely on invoking negative emotions to increase attention and stimulate behavioural change. ${ }^{12} 13$ These issues are relevant in the Australian context where smoking rates are low, comprehensive tobacco control policies are in place and smokers are more likely to be members of disadvantaged groups. As a result of this combination of factors, new approaches to smoking cessation advertising need to (1) accommodate the particular characteristics and needs of the smaller cohort of remaining smokers and (2) reflect the new social and physical environments in which they make their smoking-related decisions. The results of previous studies conducted in periods with higher smoking rates and less restrictive policies are unlikely to provide adequate guidance for new campaigns in the current environment.

To address this issue, a three-phase methodology was used to (1) identify the major concerns of current smokers and those who have recently quit, (2) develop and test a series of messages relating to these concerns and (3) implement and evaluate an advertising campaign based on the message appeal found to be most relevant. Ethics clearance was obtained from the Curtin University Human Research Ethics Committee for the two quantitative phases, and the qualitative phase was conducted by a social research agency according to the ethical 
standard requirements of the Marketing and Social Research Society of Australia. The outcome measures of interest were recall, believability, perceived relevance and quitting/reducing behaviours. Throughout the research, smokers were defined as those who smoke at least one cigarette per day or seven per week, and recent quitters were defined as those who had stopped smoking within the past 12 months.

\section{PHASE 1}

Method

To identify major concerns and triggers for attempting to quit, 10 focus groups with current smokers $(\mathrm{n}=77)$ and eight individual interviews with recent quitters were conducted. This combination of methods was selected because it was anticipated that some factors pertaining to quitting were very personal and individual interviews would allow greater levels of disclosure and hence a more in-depth understanding of the issues that ultimately resulted in a successful quit attempt. The focus groups with current smokers permitted access to a larger number of study participants and facilitated interaction between smokers, which was useful for gaining insight into the relative importance of particular issues. Experienced moderators ensured all participants contributed to the group discussion by using prompting and probing techniques.

Participants were systematically randomly recruited from a database of Western Australian adults who had previously participated in telephone surveys on behalf of a variety of health and other organisations. Screening criteria were applied to ensure diversity of gender, age, and lifestyle characteristics (eg, family vs singles and couples with no children). The resulting phase 1 sample comprised 35 males and 50 females. All participants were between 25 and 54 years of age and living in lower to medium socioeconomic suburbs in the Perth metropolitan area. Almost half of the sample $(n=41)$ reported having children under the age of 18 years.

The individual interviews were conducted at participants' homes where quitters could share their stories in their 'real-life' environments, and the focus groups were conducted on the premises of a social research agency. During the semistructured interviews and focus groups, participants were asked to discuss any events, concerns or triggers that sparked thoughts or behaviours relating to quitting. On average, the interviews lasted around an hour and the focus groups $90 \mathrm{~min}$. All sessions were digitally audio recorded and then content analysed and coded into key themes.

\section{Results}

Quitters and smokers identified a range of factors that influenced their thoughts of quitting or actual quitting behaviours. These included the negative emotions experienced resulting from the social unacceptability of smoking (especially shame and guilt), long-term health consequences (particularly cancer), reduced fitness (eg, shortness of breath from running, playing a sport, walking up the stairs) and the financial cost of smoking. Of these, shame, guilt and health were reported to be the most substantial concerns. The coding framework and illustrative quotes for each theme are shown in table 1.

While most of the identified concerns have been well documented and are commonly used in tobacco control advertisements, shame has not. This is despite shame being recognised as a potential motivator for undertaking health behaviours such as quitting smoking and reducing alcohol consumption. ${ }^{10}{ }^{14}$ Shame is related to guilt in that both are the emotional consequences of transgressing one's moral code. ${ }^{15}{ }^{16}$ However, shame is postulated to differ from guilt due to a stronger focus on others' negative evaluations of the self (as opposed to selfevaluations) and the experience of a more global negative evaluation of the self (as opposed to a negative evaluation of just the behaviour)..$^{10} 1415$

The salience of shame was indicated by the intensity of emotion expressed when talking about these feelings and the time spent on the topic by the participants. As reflected in table 1, participants reported that their experience of shame stemmed from the increased social unacceptability and stigma attached to smoking, signalled by the lower prevalence of smoking among the broader community and the 'dirty looks' and 'raised eyebrows' they received from others. The legislation requiring smoke-free workplaces and other venues was also seen to emphasise the moral transgression of smoking. Even at private events, many participants reported having to withdraw from the larger group to smoke, which contributed to their sense of isolation and segregation.

Some participants shared their experiences of others overtly changing their opinions of them once they became aware of their smoking status. Females seemed to be especially sensitive about this issue, particularly when trying to attract a partner or meet new friends. Some participants talked about going to great lengths to minimise their shame by covering up or hiding their smoking from others. Common cover-up strategies included applying deodorants to disguise the smell on clothes and using mouthwash and chewing gum to freshen their breath.

Participants were particularly concerned with hiding their smoking from family and friends, and some avoided smoking in any public locations. While hiding behaviours were reported by a broad range of participants, those who were parents appeared very keen to ensure their children did not witness the act.

\section{PHASE 2}

Phase 2 was designed to test the relative impact of the three strongest themes identified in the qualitative data: shame, guilt and health concerns. The effectiveness of a health-focused approach was tested using three previous antismoking television advertisements that conveyed the risk of lung cancer and stroke. The utility of a guilt approach was also tested using a previous antismoking television advertisement that communicated the emotional pain children would feel if a parent developed lung cancer. As a fully finished execution using a shame appeal did not exist, a shame message was tested using a string of storyboards with a voice over (an animatic) to depict various situations of people hiding their smoking from others.

The testing procedure and questionnaire items were based on standard commercial copy testing procedures ${ }^{17}$ adapted for pretesting health communications. ${ }^{18}$ In total, 375 smokers (defined as smoking at least one cigarette a day or seven per week) aged 18-54 years were randomly recruited via telephone and invited to participate in research on antismoking television advertisements. Appropriately screened individuals were randomly assigned to view one of the five advertisements ( $n=75$ per ad). Quotas were used to achieve approximately equal gender splits and distribution across three age groups (18-29, 30-44, 4554 years). The respondents received $\$ 50$ for attending the ad testing interview.

Respondents viewed the advertisements on a 19-inch monitor in an ad test room on a university campus. Each advertisement was shown twice with a $5 \mathrm{~s}$ gap between screenings. At the end of the second showing of the advertisement, respondents completed a self-administered questionnaire. The questionnaire measured respondents' reactions to the advertisement, message 
Table 1 Phase 1 coding framework and illustrative quotes

\begin{tabular}{|c|c|c|}
\hline Theme & Definitions & Illustrative quotes \\
\hline \multirow[t]{2}{*}{ Health } & - Long-term health consequences (eg, cancer, living a shorter life) & $\begin{array}{l}\text { "I want to be healthy and live a long life" (male, } 30-54 \text {, former smoker, } \\
\text { parent). } \\
\text { "I don't want to have the doom and gloom of maybe dying of lung cancer } \\
\text { one day" (female, } 25-39 \text {, smoker, no children) }\end{array}$ \\
\hline & $\begin{array}{l}\text { Short-term health consequences (eg, increased coughing, harder to } \\
\text { recover from colds, lower immunity, shortness of breath, harder to } \\
\text { breathe) }\end{array}$ & $\begin{array}{l}\text { "My health...my lung capacity was pathetic... waking up, coughing and } \\
\text { phlegm" (male, 30-54, former smoker, parent) } \\
\text { "When you can't go up that flight of stairs or run on the treadmill like you } \\
\text { used to, it hits you" (male, 25-39, smoker, no children) }\end{array}$ \\
\hline \multirow[t]{2}{*}{ Emotional } & $\begin{array}{l}\text { Shame (eg, smoking viewed negatively by others, smokers seen } \\
\text { differently, changes in the way people see you, embarrassed smoking in } \\
\text { front of others, feel the need to hide smoking from others, feel the need } \\
\text { to remove oneself while smoking) }\end{array}$ & $\begin{array}{l}\text { "Smoking used to be cool, but now it's become something to be ashamed } \\
\text { of. I'm made to smoke in a little dark corner with a filthy can on the } \\
\text { ground as an ashtray. Like a pariah" (female, 25-39, smoker, no children). } \\
\text { "Where you are allowed to smoke is having an effect... you're not } \\
\text { becoming cool in the group, you are becoming an outsider to the group. } \\
\text { It's not something I am proud of" (male, 25-39, smoker, no children). } \\
\text { "Smokers are made to feel like a second class citizen....it's humiliating" } \\
\text { (male, 25-39, former smoker, no children) } \\
\text { "I feel ashamed if someone sees me [smoke]...so I don't smoke in public, } \\
\text { around work, other people. I only smoke at home or all by myself" (female, } \\
30-54, \text { smoker, no children) } \\
\text { "I go hide in the shed" (male, 30-54, smoker, parent). "You feel like a } \\
\text { leper, or like you have two heads" (female, 25-39, quitter, parent) } \\
\text { "I always want to go around the corner and hide to have a cigarette...so } \\
\text { my kids don't see me" (female, 30-54, smoker, parent) }\end{array}$ \\
\hline & $\begin{array}{l}\text { Guilt (eg, smoking is the wrong thing to do to yourself/harms self, harms } \\
\text { others, passive smoking, poor role model for children, makes others } \\
\text { worry) }\end{array}$ & $\begin{array}{l}\text { "I feel guilty, cause I want a cigarette and I am not spending time with the } \\
\text { kids" (female, 30-54, smoker, parent) } \\
\text { "They are so worried about mummy dying...they've cried sometimes. You } \\
\text { feel bad" (female, 30-54, smoker parent) } \\
\text { "I'm concerned I am being a hypocrite and not setting a good example for } \\
\text { my kids" (male, 30-54, smoker, parent) }\end{array}$ \\
\hline Environmental & $\begin{array}{l}\text { Lower prevalence (eg, less smoking in the community and among friends/ } \\
\text { peers/colleagues/ partners) }\end{array}$ & "Less people smoke now" (male, 25-39, smoker, no children) \\
\hline & - Increased legislation requiring smoke-free venues/workplaces & $\begin{array}{l}\text { "It's quite inconvenient as you have to remove yourself from a social } \\
\text { situation to go and smoke" (male, 25-39, smoker, no children) }\end{array}$ \\
\hline Financial & Cost of cigarettes/affordability & $\begin{array}{l}\text { "Every time the cost goes up it crosses your mind to stop..." (male, } \\
30-54 \text {, smoker, parent) }\end{array}$ \\
\hline & $\begin{array}{l}\text { Cost of deodorants/mouthwash/chewing gum/lollies to freshen breath or } \\
\text { cover up smoking }\end{array}$ & $\begin{array}{l}\text { "Spending a fortune, constantly gargling mouthwash and chewing gum" } \\
\text { (female, 25-39, smoker, no children) }\end{array}$ \\
\hline Cosmetic & $\begin{array}{l}\text { Smell of smoke /bad breath } \\
\text { Yellow fingers/teeth/staining } \\
\text { Wrinkles/ageing skin }\end{array}$ & $\begin{array}{l}\text { "People say 'Go away, you stink!'. My nephews and nieces don't want to } \\
\text { kiss me" (female, 25-39, smoker, no children) } \\
\text { "It got to the stage I started to suck lollies all day" (female, 30-54 former } \\
\text { smoker, parent) }\end{array}$ \\
\hline
\end{tabular}

take-out and believability, and impact of the ad on quit intentions.

As shown in table 2, the shame message performed as well as, or better than, the guilt and health messages on the key measures. There were no significant differences in results by age or gender.

When asked about the main messages of the shame ad, the key differential responses were that 'Smoking affects people's opinions of you' $(28 \%)$ and 'Smoking is not socially acceptable' $(13 \%)$. Neither of these messages was strongly elicited from the health or guilt advertisements (0-3\%). Similar themes were nominated by respondents when they were asked which aspects of the ad they most liked, with comments relating to smoking affecting others' opinions of the individual being among the most frequent responses. Other messages of the shame ad that were also key take-outs of the other ads tested were 'Quit smoking' (32\%) and 'Think of the impact your smoking has on your family/other people' (21\%).

Overall, the analyses of the ad test results demonstrated that the shame message performed well across the various measures. While the novelty of the shame message may have contributed to the results, this benefit may have been offset by the fact that it was tested as an animatic while the other themes were tested as finished ads, potentially placing the shame message at a disadvantage. ${ }^{19}$ These results, combined with the qualitative findings, indicated that focusing on shame may be an effective approach to motivate smokers to quit.

\section{PHASE 3}

In phase 3 of the study, a television campaign was developed that was titled 'How You're Seen'. Reflecting the negative selfevaluations and hiding behaviours that were associated with shame by the participants in the qualitative phase of the research, the $45 \mathrm{~s}$ advertisement depicted individuals choosing to remove themselves from the company of others to smoke alone, but being observed by loved ones or passers-by. Specifically, four scenes showed a man smoking out in the rain being watched by a male colleague, a woman smoking in her driveway being observed by her husband, a woman smoking by the side of a house during a party and being seen by another woman passing by, and a father smoking in a shed being watched by his daughter. After each scene the voiceover says: 'Is this how your workmates/partner/friends/kids see you?' The advertisement cuts to a close up of the smoker in the last scene and the voiceover says, 'Is this how you want to see yourself?'. 


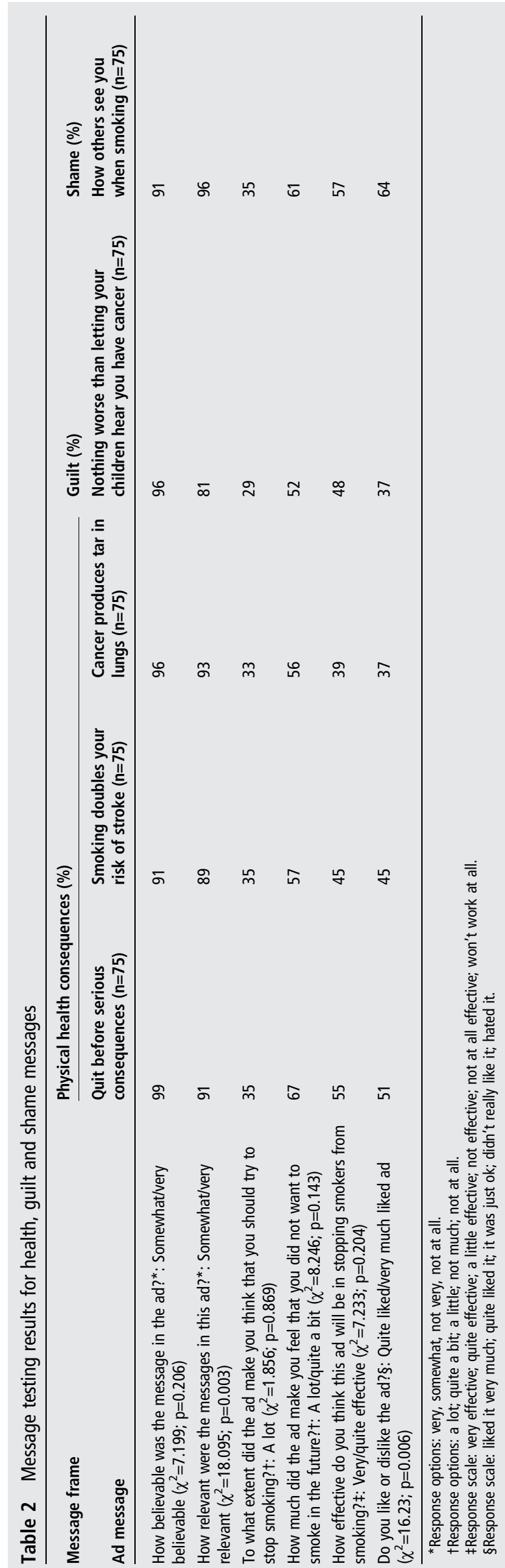

The advertisement was broadcast from 22 April to 19 May 2012 inclusive at 1091 TARPS on all major metropolitan commercial stations and regional stations. A postcampaign evaluation was conducted within 3 weeks of the campaign coming off air. Random digit dialling from the White Pages telephone directory was used to select households for inclusion in a telephone survey. Respondents were Western Australian residents aged 25-54 years who either currently smoked (at least one cigarette a day or seven per week) or had successfully quit smoking within the previous 4 or 5 weeks. Quotas were set to ensure a total sample of 200 respondents with a ratio of $70 \%$ metropolitan to $30 \%$ regional residents and equal gender and age representation.

The postcampaign evaluation results indicated that the "How You're Seen' advertisement was effective (table 3). Total awareness of the ad (cued recall and prompted awareness combined) was $78 \%$. There were no significant differences in the levels of total awareness according to gender $(\mathrm{p}=0.290)$, age group $(\mathrm{p}=0.619)$ or location $(\mathrm{p}=0.475)$.

The 'How You're Seen' ad also achieved a high level of personal relevance ( $72 \%$; including $26 \%$ 'very' relevant) reflecting the reported experiences of many participants in the qualitative phase of the study. There were no significant differences in results by gender $(p=0.574)$, age group $(p=0.810)$ or location $(\mathrm{p}=0.778)$.

Finally, in terms of behavioural outcomes, 1 in 2 respondents $(54 \%)$ reported that they had successfully quit (2\%), attempted to quit $(16 \%)$ or cut down the number of cigarettes they smoke $(36 \%)$. Once again, there were no significant differences in terms of these self-reported behaviours according to gender $(\mathrm{p}=0.249)$, age group $(\mathrm{p}=0.396)$ or location $(\mathrm{p}=0.496)$.

Take-out of a relevant message was high at 94\% among respondents who could recall the ad. The main perceived message was 'Smoking makes you a social outcast' (52\%), followed by 'You have to hide your smoking from others' (22\%) and 'This is how smokers are seen by others' (18\%).

\section{DISCUSSION}

In this study, an initial qualitative phase and a subsequent message testing phase indicated that shame is a highly salient emotion for the shrinking minority of Western Australians who smoke. Based on these results, a television advertising campaign was developed that attempted to reflect these feelings of shame for the purpose of motivating cessation attempts. The advertisement performed well in terms of awareness, believability, perceived relevance and behavioural outcomes. Overall, the results of this three-phase study suggest that shame appeals in tobacco control advertisements can be effective in the context of low smoking rates and regulations that limit smoking in public venues and prohibit tobacco promotion.

The study outcomes have theoretical value due to the lack of evidence relating to how negative emotions used in prosocial advertisements are processed and the possible mechanisms by which such approaches may influence audiences. ${ }^{11} 16{ }^{20}$ In particular, while it is recognised that the use of negative emotions can assist in attracting attention due to emotional arousal, ${ }^{20} 21$ the process of moving audiences beyond attention to behavioural change is more complex and less understood. ${ }^{10}$ This study found that a shame message was effective in attracting attention and stimulating behavioural change in the form of quit attempts and reducing tobacco use. As suggested by behavioural theories (eg, Health Belief Model and the Elaboration Likelihood Model), the high scores for perceived personal relevance are likely to have contributed to this outcome. This 
Table 3 Phase 3 results

\begin{tabular}{|c|c|c|c|c|c|c|c|}
\hline & \multirow[b]{2}{*}{ Total (\%) } & \multicolumn{2}{|c|}{ Gender (\%) } & \multicolumn{2}{|c|}{ Age (years; \%) } & \multicolumn{2}{|c|}{ Location (\%) } \\
\hline & & Male & Female & $25-34$ & $35-54$ & Metro & Country \\
\hline Total awareness & 78 & 76 & 82 & 76 & 79 & 77 & 82 \\
\hline $\begin{array}{l}\text { Would you say the ad was relevant to you personally or not } \\
\text { relevant to you personally? }{ }^{*} \text { : Very relevant/relevant }\end{array}$ & 72 & 74 & 70 & 73 & 71 & 71 & 73 \\
\hline $\begin{array}{l}\text { Have you successfully quit, tried to quit or reduce the amount } \\
\text { you smoke in the past } 4 \text { or } 5 \text { weekst: Yes }\end{array}$ & 56 & 54 & 58 & 54 & 56 & 55 & 57 \\
\hline
\end{tabular}

emphasises the importance of engaging in ongoing research to identify smokers' key concerns to ensure that messages used in tobacco control advertisements appropriately reflect changing social and regulatory environments.

Self-congruency theory highlights the need to align messages with self-perceptions. ${ }^{22}$ The qualitative data strongly indicated that shame can be a common emotion experienced by smokers where they constitute a minority. This was especially evident in the study participants' descriptions of their hiding behaviours while smoking. By utilising depictions of shame that reflect smokers' experiences as a minority whose actions are not socially condoned, the campaign was considered to be credible, relevant and capable of motivating behavioural change. Previous work has cautioned against invoking psychological reactance due to perceived manipulative intent. ${ }^{23} 24$ In the present study, a message depicting smoking-related shame in a manner congruent with individuals' experiences received relatively high likeability scores and thus appeared to avoid psychological reactance. Formative research designed to inform future campaigns should therefore consider both the types of negative emotions relevant to the decision to smoke and the 'dose' of these emotions to ensure that subsequent campaigns depict the experience of the emotion in realistic and meaningful ways.

A further theoretical contribution of the present study is support for the inclusion of shame in typologies of negative emotions relevant to advertising messages. ${ }^{10}$ This particular emotion tends to be omitted from conceptualisations of the range of negative emotions relevant to prosocial advertisements. ${ }^{11} 21$ Based on the study participants' responses in the context of smoking, it seems likely that this emotion would be relevant to other socially unacceptable behaviours and hence would be appropriate for inclusion in typologies designed to provide researchers with the spectrum of potential emotional responses to prosocial messages.

A further consideration in the choice of message appeals is the possibility of unintended consequences. The use of negative emotions in advertising can be considered unethical if perceived as exploitative or manipulative, or where the audience is exposed to images or messages considered to be offensive. ${ }^{13}$ Audience members may or may not be the intended recipients of the message, and invoking negative emotions in people for whom the message has no value can also be considered unethical. ${ }^{12}$ This is especially relevant for those with health conditions that are often associated with smoking who may be stigmatised for their condition despite being a non-smoker. These issues all need to be considered when assessing the appropriate use of negative emotions in health promotion campaigns.

An important issue is thus whether advertisements using a shame approach are more or less unethical relative to other approaches (eg, where advertisements trigger health fears or invoke guilt about the harm that may be inflicted on loved ones as a result of one's smoking). Health and guilt themes are routinely used in tobacco control advertisements in Australia and elsewhere, ${ }^{8} 9$ suggesting that potential negative outcomes may be considered acceptable because of the broader positive health benefits for individuals and populations. Participants in the qualitative phase of the present study reported already experiencing a range of negative emotions relating to their smoking. This indicates that messages that focus on feelings such as shame may be reflecting actual experiences rather than inflicting the emotion on individuals who would otherwise remain shamefree. In addition, there is some evidence that smokers already feel stigmatised by other forms of tobacco control that aim to de-normalise smoking, making them feel like 'lepers'. ${ }^{25}$ Antismoking advertisements that explicitly focus on feelings of shame may therefore be building on the effects of existing strategies that are achieving the same outcome, albeit unintentionally. The reported efforts to quit/reduce and the apparent lack of psychological reactance among those smokers in the present study who recalled seeing the advertisement suggest that the scenarios depicted were viewed as realistic and reasonable and were capable of motivating behavioural change. They did not appear to be perceived as overstating the risk of shame nor invoking emotions that were not already closely aligned with smoking.

This study had several limitations. In the first instance, although the emotion of shame was a central construct in the study, the extent to which smokers experienced shame prior to and after being exposed to the advertisement was not measured. Future research may seek to address this by quantifying shame elicitation resulting from exposure to shame-based messages. Second, as the focus of the study was on the ability of various message appeals to influence smokers, non-smokers were not included. This prevents the identification of unintended consequences on other population segments. Third, the study design for phase 3 did not include intentional recruitment of smokers who were not exposed to the ad, resulting in an inadequate number of non-exposed respondents to allow meaningful comparison between the responses of those who had and had not seen the ad. Without a control group, this leaves open the possibility that factors other than exposure to the ad contributed to the results. To address these issues, future studies may be designed to include smokers, non-smokers and a control group of non-exposed smokers to permit further analyses. Finally, it is likely that the novelty of the shame-based approach influenced the outcomes. This suggests that effectiveness may be reduced over time, however in the interim the approach appears to have the potential to encourage smokers to attempt cessation.

To conclude, this study contributes to the limited body of literature relating to the conditions under which the use of shame 
may be effective in tobacco control advertisements. The results suggest that shame appeals may motivate smokers to attempt quitting or reduce their smoking in an environment where they are members of a small minority and supportive legislation exists to discourage smoking in public places. Further research would be needed to determine the extent to which shame appeals would be appropriate in countries with higher smoking rates and fewer constraints on public smoking.

\section{What this paper adds}

\section{What is already known on this subject?}

- Tobacco control efforts to date have relied heavily on mass media to educate the public about the harms of smoking.

- Past mass media campaigns have typically used health and guilt messages to persuade smokers to quit.

What important gaps in knowledge exist on this topic?

- In Australia there is a relatively small segment of smokers who have remained immune to past campaigns, but little is known about which message appeals would be most effective in encouraging them to quit.

\section{What this study adds?}

- The study results suggest that messages characterised by a shame appeal, as depicted by smokers' hiding behaviours, may be more effective than guilt and health appeals in motivating smokers to quit in an environment where they are members of a small minority and supportive legislation exists to discourage smoking in public places.

Acknowledgements The authors acknowledge Ms Fiona Phillips (Cancer Council Western Australia), Dr Chad Lin and Nicole Biagioni (Curtin University) and Dr Chris Marchegiani (Painted Dog Research).

Contributors CA and CC managed data collection. CA conducted the statistical analyses. CA and SP performed the literature review and took primary responsibility for writing the paper. All authors contributed to the conceptualisation of the study and the preparation of the manuscript. All authors approved the final version of the manuscript.

Funding The work was supported by Cancer Council Western Australia, the Western Australian Department of Health (Service Agreement C05651) and Western Australian Health Promotion Foundation (Grant Number 30495).

\section{Competing interests None.}

Ethics approval The quantitative phases were approved by the Curtin University Human Research Ethics Committee. The qualitative data collection was conducted by a social research agency in accordance with the ethical standard requirements of the Marketing and Social Research Society of Australia.

Provenance and peer review Not commissioned; externally peer reviewed.

\section{REFERENCES}

1 Durkin S, Brennan E, Wakefield M. Mass media campaigns to promote smoking cessation among adults: an integrative review. Tob Control 2012;21:127-38.
2 Bala M, Strzeszynski L, Cahill K. Mass media interventions for smoking cessation in adults. Cochrane Database Syst Rev 2008;(1):CD004704.

3 Australian Institute of Health and Welfare (AU). Tobacco smoking (NDSHS 2013 key findings): Australian Institute of Health and Welfare (AU); [cited 5 August 2014]. Available from: http://www.aihw.gov.au/alcohol-and-other-drugs/ndshs/2013/ tobaccol

4 Office for National Statistics (UK). Statistical bulletin: Key Findings from the Integrated Household Survey: January 2012 to December 2012 (Experimental Statistics): Office for National Statistics (UK); [cited 5 August 2014]. http://www.ons. gov.uk/ons/rel/integrated-household-survey/integrated-household-survey/january-todecember-2012/stb-integrated-household-survey-january-to-december-2012. html\#tab-Smoking-prevalence.

5 Centers for Disease Control and Prevention (US). Current cigarette smoking among adults—United States, 2005-2012. MMWR Morb Mortal Wkly Rep 2014;63:29-34: Centers for Disease Control and Prevention (US); [cited 5 August 2014]. http://www.cdc.gov/mmwr/preview/mmwrhtml/mm6302a2.htm?s _ cid $=$ mm6302a2 $\mathbf{w} \#$ tab

6 Freeman B, Gartner C, Hall W, et al. Forecasting future tobacco control policy: where to next? Aust N Z J Public Health 2010;34:447-50.

7 Gartner $\mathrm{CE}$, Barendregt JJ, Hall WD. Predicting the future prevalence of cigarette smoking in Australia: how low can we go and by when? Tob Control 2009;18:183-9.

8 Brennan E, Durkin SJ, Cotter T, et al. Mass media campaigns designed to support new pictorial health warnings on cigarette packets: evidence of a complementary relationship. Tob Control 2011;20:412-18.

9 De Meyrick J. Tobacco smoking's changing trajectory in Australia. J Bus Res 2010;63:161-5.

10 Brennan L, Binney W. Fear, guilt, and shame appeals in social marketing. J Bus Res 2010;63:140-6.

11 Cohen EL, Shumate MD, Gold A. Anti-smoking media campaign messages: theory and practice. Health Commun 2007;22:91-102.

12 Lupton D. The pedagogy of disgust: the ethical, moral and political implications of using disgust in public health campaigns. Criti Public Health 2014;25:4-14.

13 Williams KC. Improving fear appeal ethics. J Acad Bus Ethics 2011;5:1-24.

14 Agrawal N, Duhachek A. Emotional compatibility and the effectiveness of antidrinking messages: a defensive processing perspective on shame and guilt. J Mark Res 2010;47:263-73.

15 Tangney JP, Stuewig J, Mashek DJ. Moral emotions and moral behavior. Annu Rev Psychol 2007;58:345.

16 Nelissen R, Breugelmans SM, Zeelenberg M. Reappraising the moral nature of emotions in decision making: the case of shame and guilt. Soc Personal Psychol Compass 2013;7:355-65.

17 Rossiter JR, Percy L. Advertising and promotion management. McGraw-Hill Book Company, 1987.

18 Donovan RJ, Jalleh $\mathrm{G}$, Carter $\mathrm{O}$. Tobacco industry smoking prevention advertisements' impact on youth motivation for smoking in the future. Soc Mar $Q$ 2006;12:3-13.

19 Braun-Latour KA, Zaltman G. Memory change: an intimate measure of persuasion. J Advert Res 2006;46:57-72.

20 Leshner G, Vultee F, Bolls PD, et al. When a fear appeal isn't just a fear appeal: the effects of graphic anti-tobacco messages. J Broadcast Electron Media 2010:54:485-507.

21 Richardson S, McNeill A, Langley TE, et al. The impact of televised tobacco control advertising content on campaign recall: evidence from the International Tobacco Control (ITC) United Kingdom Survey. BMC Public Health 2014;14:432.

22 Chang C. Enhancing the effectiveness of antismoking messages via self-congruent appeals. Health Commun 2009;24:33-40.

23 Cotte J, Coulter RA, Moore M. Enhancing or disrupting guilt: the role of ad credibility and perceived manipulative intent. J Bus Res 2005;58:361-8.

24 Turner MM, Underhill JC. Motivating emergency preparedness behaviors: the differential effects of guilt appeals and actually anticipating guilty feelings. Commun Q 2012;60:545-59.

25 Ritchie D, Amos A, Martin C. Public places after smoke-free-a qualitative exploration of the changes in smoking behaviour. Health Place 2010;16:461-9. 